\title{
A Massive Congenital Intracranial-orbital Immature Teratoma Tracing Trigeminal Nerve Pathway in One Monozygotic Twin: Report of a Case and Review of the Literature
}

\section{Guive Sharifi ${ }^{1}$, Mehrdad Hosseinzadeh Bakhtevari², Farahnaz Bidari Zerehpoosh ${ }^{3}$, Masood Saberi ${ }^{4}$, Mona Rezaei ${ }^{5}$ and Omidvar Rezaei ${ }^{6}$}

${ }^{1}$ Associate professor of neurosurgery, Department of Neurosurgery, Loghman e Hakim hospital, Shahid Beheshti University of Medical Sciences, Tehran-Iran

${ }^{2}$ Clinical Neurosurgeon, Department of Neurosurgery, Loghman e Hakim hospital, Shahid Beheshti University of Medical Sciences, Tehran-Iran

${ }^{3}$ Assistant professor of pathology, Department of Neuropathology, Loghman e Hakim hospital, Shahid Beheshti University of Medical Sciences, Tehran-Iran

${ }^{4}$ Clinical neurosergeon, Department of Neurosurgery, Erfan Hospital, Tehran-Iran

${ }^{5}$ Medical researcher, Department of Neurosurgery, Loghman e Hakim hospital, Shahid Beheshti University of Medical Sciences, Tehran-Iran

${ }^{6}$ Professor of neurosurgery, Department of Neurosurgery, Loghman e Hakim hospital, Shahid Beheshti University of Medical Sciences, TehranIran

Corresponding author: Mehrdad Hosseinzadeh Bakhtevari, Department of Neurosurgery, Loghman Hakim Hospital, Shahid Beheshti University of Medical Sciences, Tehran-Iran, Tel: +9821-55414065; Fax: +9821-55414065; E-mail: mhbakhtevari@yahoo.com

Received: Jan 22, 2016; Accepted: Feb 10, 2016; Published: Feb 15, 2016

\section{Abstract}

Background: Congenital intracranial teratomas are extremely rare tumors, which may extend through the extracranial structures, namely orbit, and pose difficulties in determining of original site and also in the surgical procedures.

Methods and materials: In this paper, we presented two newborn male monozygotic twins in which only one twin had a proptosis of the right eye. The magnetic resonance imaging (MRI) revealed a huge tumor along a trigeminal nerve that involved orbit, wall of cavernous sinus, infratemporal fossa, and brain stem. Because of the large involvement of this tumor, the patient underwent a subtotal resection of the middle cranial fossa and debulking of intra orbital portion. The histopathological findings demonstrated a congenital immature teratoma.

Result: To date, the patient is treated with adjuvant chemotherapy, and the other twin remains healthy, with normal brain CT scan.

Conclusion: To our knowledge, given the low incidence of congenital teratomas, there is no certain treatment for these tumors, and perhaps this report is the first case of congenital immature teratoma presented in intracranial or orbital structures in only one monozygotic twin.

Keywords: Congenital; Immature teratoma; Middle fossa; Orbit; Monozygotic twins; Trigeminal nerve

\section{Introduction}

Congenital tumors are rare, representing less than $1 \%$ of all childhood tumors. Of these, $10 \%$ arise from the central nervous system, and approximately $30-50 \%$ are teratomas $[1,2]$. The most common site for congenital teratomas is the sacrococcygeal region, however they also occur in the neck, mediastinum, orbit, and intracranial region $[1,3,4]$.

Teratomas are approximately $0.5 \%$ of all intracranial tumors $[1,4]$. which may extend into the extra cranial structures such as neck or orbit [5-7].

Generally, teratomas are true neoplasm derived from pluripotent cells and composed of tissues originating from all three germinal layers: endoderm, mesoderm, and ectoderm [8-10]. They also have a heterogeneous histologic appearance that may include cystic or solid areas with organoid patterns, as well as mature or immature components $[3,11]$.

Although congenital intracranial immature teratomas are very rare lesions, they are sometimes large enough to endanger life. They are usually hemorrhagic, preventing easy surgical removal, and resulting in a dismal prognosis $[12,13]$.

Thus, we presented an unusual case of a huge immature congenital teratoma with an extension through the intracranial cavity and also orbit in one newborn male monozygotic twin. 


\section{Methods and Materials}

\section{Case report}

Two male monozygotic twins were born by cesarean delivery at 34 weeks of gestation following an uneventful gestation and regular prenatal examinations.

The first infant had a birth weight of $2,300 \mathrm{~g}$, length of 47 $\mathrm{cm}$, head circumference of $33.5 \mathrm{~cm}$, and an Apgar's score of 10 at $1 \mathrm{~min}$, and the measurement of second-born infant's weight, length, head circumference, Apgar's score were 2,200 $\mathrm{g}, 46 \mathrm{~cm}, 33 \mathrm{~cm}$, and 10 at $1 \mathrm{~min}$, respectively. Although all of these physical factors were normal and no family history of congenital malformations were mentioned by parents, who also had a healthy 7-year-old boy, immediately after birth, the first twin revealed a proptosis of right eyeball, whereas the second one was completely healthy.

On examination, the patient had a unilateral proptosis of the right eye. The proptosis was axial, non-reducible, and was accompanied by a huge chemosis hiding partially the eyeball. However, pupils were reactive to light, and eye movements appeared to be full. In addition, the infant did not have any other systemic abnormality.

Magnetic resonance imaging (MRI) demonstrated a large heterogeneous mass containing both solid and cystic components extending through orbit, middle fossa, infratemporal fossa, and brain stem (Figure 1). A mass was $3 \times$ $3 \times 5 \mathrm{~cm}$ in the intracranial cavity with an extension about 3 $\mathrm{cm}$ through the infratemporal fossa.

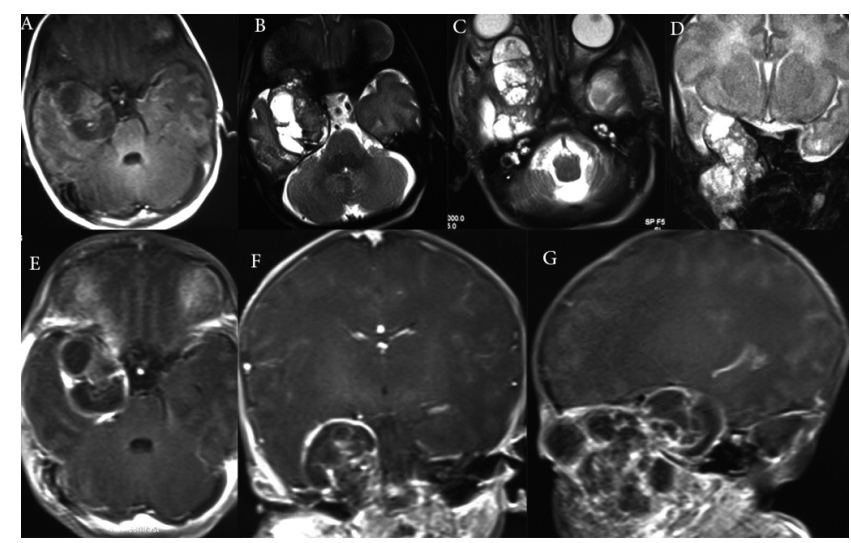

Figure $1 \mathrm{MRI}$ revealed cystic mass in the right middle cranial fossa with extension in to the orbital region and brain stem which showed heterogeneous enhancement after gadolinium injection. (A: T1-weighted MRI, B,C,D: T2weighted images, E,F,G: T1-weighted after gadolinium contrast)

The patient underwent a middle fossa craniotomy. Interoperatively, spread of the tumor along the trigeminal nerve was detected. The tracing was from the enlarged superior orbital fissure along the lateral wall of cavernous sinus and then into the middle cranial fossa, which passed down through the tentorium to the brainstem. Additionally, the tumor had an extracranilal extension to the right infratemporal fossa through foramen ovale and foramen spinosum.

Considering the optic nerve involvement, it was advised that complete excision carried a high risk of visual impairment and thus a more conservative approach should be taken. Therefore, subtotal resection of the middle cranial fossa and debulking of the orbital portion of tumor were performed, but the intra orbital part and the brainstem portion left to avoid damaging normal structures.

Postoperatively, the infant was transferred to neonatal intensive care unit and neurological examinations were normal. Then, the patient recovered well and was discharged after 5 days.

Macroscopically, the tumor was grayish-tan and fleshy, with small cysts filled with mucinous fluid and foci of hemorrhages. Histopathological examination of the excised tissue indicated a variety of tissues derived from all germinal layers. Squamous nests, choroid plexus papillary structure and respiratory epithelium (Figure 2A), mucinous glands, and cysts were identified. Additionally, in 2 LPF/slides, solid sheets of primitive neuroepithelial tissue with rosettes and abortive channel formations were observed (Figure 2B). Small islands of hyaline cartilage were also noted in the background of fetal mesenchymal tissue (Figure $\mathbf{2 C}$ ) and necrosis was scattered. Considering the evaluation of neural components and grading of tumor, histologic diagnosis was consistent with an immature congenital teratoma, Norris grade 2.

To date, the patient is survived after 3 months and treated with adjuvant chemotherapy, and the non-affected twin is completely healthy.

\section{Discussion}

Teratomas are the most frequent type of congenital CNS tumors $[14,15]$ which may arise in several locations, including midline, cerebral hemispheres, pineal, hypothalamic area, suprasellar region, 3rd ventricle $[16,17]$ and less frequently in basal ganglia, cavernous sinus, and cerebellopontine angle $[4,18]$ However, since the brain is replaced by tumor, identifiable anatomical landmarks may be lost, making it practically impossible to determine the exact site of origin [19-21].

Generally, several forms of fetal intracranial teratomas have been described, including huge tumors replacing the intracranial contents, smaller ones producing hydrocephalus, large intracranial teratomas with extension into the orbit, pharynx, oral cavity, or neck, and incidentally discovered tumors in stillborn infants [22]. Similar to the reports that intracranial teratomas may erode through the skull and extend into the extra cranial structures, [5-7] in the present case, the teratoma was extending along the trigeminal nerve from the brainstem, through the infratemporal fossa, along the lateral 
wall of cavernous and then into the superior orbital fissure, which were relatively uncommon areas for congenital teratomas. Since it was a huge mass of teratoma in both intracranial and orbital structures, identification of the exact original site of teratoma was very difficult and led us to classify this lesion both as a congenital intracranial teratoma and a congenital orbital teratoma.
Intriguingly, congenital orbital teratomas are extremely rare. They present with unilateral proptosis $[23,24]$ and may be infrequently accompanied by intracranial extension from an adjacent space, such as the paranasal sinuses, pterygopalatine fossa, or cavernous sinus which may result in a challenge in the surgical procedure, as occurred in our case [24].

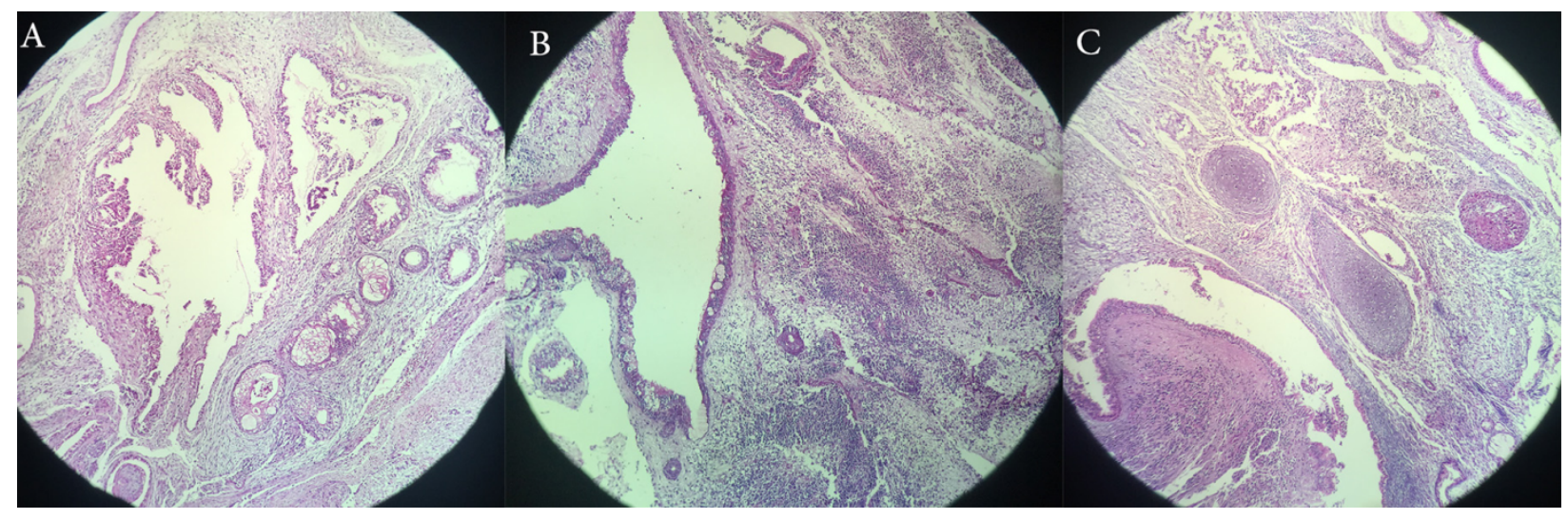

Figure 2A) Mature elements such as squamous nests, papillary structures (choroid plexus), and mucinous glands are noted as well as ciliated respiratory epithelium. (B) Mature parts (mostly respiratory mucosa) are seen in the left side and immature neuroepithelium in the right. (C) Cartilaginous islands are embedded in the center between mesenchymal and respiratory tissues

Histologically, the teratomas are classified into three groups, based on the specific types of cells and tissues present in the tumor. These are (1) mature teratomas that contain fully differentiated tissues of ectoderm, mesoderm, and endoderm; (2) immature teratomas that consist of cell populations that retain their embryological features and contain primitive components from all or any of the germ cell layers; and (3) malignant teratomas that contain malignant components of germ cells and embryonic undifferentiated cells $[4,25,26]$. Given the histopathological examination of our specimen, this lesion derived from all three germ cell layers with no malignant elements, and was consistent with an immature teratoma.

Some reports indicated that immature teratomas could be differentiated into mature teratomas $[27,28]$ Fukuoka et al. suggested that, chemotherapeutic treatment diminished the aggressiveness and hemorrhagic nature of the tumor and allowed a second surgery to complete resection of tumor. They presented a case of congenital intracranial immature teratoma of the posterior fossa which differentiating into mature teratoma, after completion of 8 courses of neoadjuvant chemotherapy [27].

Congenital intracranial teratoma in newborns are quite common, according to our knowledge and literature review, immature teratoma tracing trigeminal nerve pathway in a monozygotic twin is an exceptionally rare event. Although congenital intracranial immature teratomas are very rare lesions, the prognosis in cases of congenital intracranial teratoma is extremely poor, with a mortality rate around
$90 \%$. In majority of the cases, it ends in intrauterine fetal death or death shortly after birth $[12,13]$.

Intra uterine ultra sonography plays an important role in detecting intracranial teratoma and associated hydrocephalous.

\section{Conclusion}

Although there have been few reports of successful chemotherapy for congenital immature teratomas, it is reasonable to support this idea that treating patients with adjuvant chemotherapy may be effective when the surgical resection is incomplete, as the tumors are often very large and involve critical brain structures, and in particular if the teratoma is of the immature type31, as was detected in the present case. However, the outcome for infants with intracranial teratomas remains very poor despite earlier detection, improvement in surgical techniques, and chemotherapeutic regimens.

Generally, to our knowledge it is the first report of congenital immature teratoma detected in intracranial or orbital structures in one monozygotic twin, while the other reports have been described only some rare cases of intracranial teratoma twin fetus in fetus [29]. Additionally, since the second twin is completely healthy, hypothesis of twin-to twin metastasis [30] or primary familial origin [31] described previously in monozygotic twins with neuroblastoma, were not mentioned in our monozygotic twins with teratoma. 


\section{Conflict of Interest}

All authors certify that they have no affiliations with or involvement in any organization or entity with any financial interest or non-financial interest in the subject matter or materials discussed in this manuscript.

"There is no funding or conflict of interest."

"There are no financial disclosures."

\section{References}

1. Isaacs HJR (1985) Perinatal (congenital and neonatal) neoplasms: A report of 110 cases. Pediatr Pathol 3: 165-216.

2. Lee JC, Jung SM, Chao AS, Hsueh C (2003) Congenital mixed malignant germ cell tumor involving cerebrum and orbit. J Perinat Med 31: 261-265.

3. Erman T, Gocer IA, Erdogan S, Gunes Y, Tuna M, et al. (2005) Congenital intracranial immature teratoma of the lateral ventricle: A case report and review of the literature. Neurol Res 27: 53-56.

4. Tobias S, Valarezo J, Meir K, Umansky F (2001) Giant cavernous sinus teratoma: a clinical example of a rare entity: case report. Neurosurgery 48: 1367-1370.

5. Arai H, Sato K, Kadota Y, Ito M, Ishimoto K, et al. (1992) Skul base reconstruction in cases of intracranial teratoma extending into the extracranial structures. Surg Neurol 38: 383-490.

6. Carstensen H, Juhler M, Bogeskov L, Laursen H (2006) A report of nine newborns with congenital brain tumours. Childs Nerv Syst 22: 1427-1431.

7. Fearon JA, Munro IR, Bruce DA, Whitaker LA (1993) Massive teratomas involving the cranial base: treatment and outcome-a two-center report. Plast Reconstr Surg 91: 223-288.

8. Milani HJ, Araujo Junior E, Cavalheiro S, Oliveira PS, Hisaba WJ (2015) Fetal Brain Tumors: Prenatal diagnosis by ultrasound and magnetic resonance imaging. World J Radiol 7: 17-21.

9. Parmar HA, Pruthi S, Ibrahim M, Gandhi D (2011) Imaging of congenital brain tumors. Semin Ultrasound CT MR 32: 578-589.

10. Rickert CH, Probst-Cousin S, Louwen F, Feldt B, Gullotta F (1997) Congenital immature teratoma of the fetal brain. Childs Nerv Syst 13: 556-559.

11. Heerema-McKenney A, Harrison MR, Bratton B, Farrell J, Zaloudek C (2005) Congenital teratoma: a clinicopathologic study of 22 fetal and neonatal tumors. Am J Surg Pathol 29: 29-38.

12. Im SH, Wang KC, Kim SK, Lee YH, Chi JG, et al. (2003) Congenital intracranial teratoma: Prenatal diagnosis and postnatal successful resection. Med Pediatr Oncol 40: 57-61.

13. Isaacs HJR (2002) Perinatal Brain Tumors: A review of 250 cases. Pediatr Neurol 27: 333-342.
14. Canan A, Gulsevin T, Nejat A, Tezer K, Sule Y, et al. (2000) Neonatal intracranial teratoma. Brain Dev 22: 340-342.

15. Johnston JM, Vyas NA, Kane AA, Molter DW, Smyth MD (2007) Giant intracranial teratoma with epignathus in a neonate. Case report and review of the literature. J Neurosurg 106: 232-236.

16. Sinha VD, Dharker SR, Pandey CL (2001) Congenital intracranial teratoma of the lateral ventricle. Neurol India 49: 170-173.

17. Takeuchi J, Handa H, Oda Y, Uchida Y (1979) Alpha-fetoprotein in intracranial malignant teratoma. Surg Neurol 12: 400-404.

18. Lesoin F, Jomin M (1987) Direct microsurgical approach to intracavernous tumors. Surg Neurol 28: 17-22.

19. Alagappan A, Shattuck KE, Rowe T, Hawkins H (1998) Massive intracranial immature teratoma with extracranial extension into oral cavity, nose, and neck. Fetal Diagn Ther 13: 321-324.

20. Bolat F, Kayaselcuk F, Tarim E, Kilicdag E, Bal N (2008) Congenital intracranial teratoma with massive macrocephaly and skull rupture. Fetal Diagn Ther 23: 1-4.

21. Lipman SP, Pretorius DH, Rumack CM, Manco-Johnson ML (2015) Fetal intracranial teratoma: US diagnosis of three cases and a review of the literature. Radiology 157: 491-494.

22. Isaacs HJR (2014) Fetal intracranial teratoma. A review. Fetal Pediatr Pathol 33: 289-292.

23. Baidya KP, Ghosh S, Datta A, Mukhopadhyay S, Bhaduri G (2014) Huge congenital teratoma containing tooth in a three-day-old neonate. Oman J Ophthalmol 7: 13-15.

24. Morris DS, Fayers T, Dolman PJ (2009) Orbital Teratoma: case report and management review. J AAPOS 13: 605-607.

25. Hunt SJ, Johnson PC, Coons SW, Pittman HW (1990) Neonatal intracranial teratomas. Surg Neurol 34: 336-342.

26. Wakai S, Arai T, Nagai M (1984) Congenital brain tumors. Surg Neurol 21: 597-609.

27. Fukuoka K, Yanagisawa T, Suzuki T, Wakiya K, Matsutani M (2014) Successful treatment of hemorrhagic congenital intracranial immature teratoma with neoadjuvant chemotherapy and surgery. J Neurosurg Pediatr 13: 38-41.

28. Yu L, Krishnamurthy S, Chang H, Wasenko JJ (2010) Congenital maturing immature intraventricular teratoma. Clin Imaging 34: 222-225.

29. Marynczak L, Adamek D, Drabik G, Kwiatkowski S, Herman SI, et al. (2014) Fetus in Fetu: A medical curiosity-considerations based upon an intracranially located case. Childs Nerv Syst 30: $357-360$

30. Tajiri T, Souzaki R, Kinoshita Y, Tanaka S, Koga Y (2010) Concordance for neuroblastoma in monozygotic twins: case report and review of the literature. J Pediatr Surg 45: 2312-2316.

31. Mosse YP, Laudenslager M, Longo L, Cole KA, Wood A, et al. (2008) Identification of Alk as a major familial neuroblastoma predisposition gene. Nature 455: 930-935. 